\title{
Plantas, Máquinas e Interafectividade
}

\section{Plants, Machines and the Interlacing of Affective Bonds}

\section{Resumo:}

A presente comunicação investiga o acoplamento entre plantas e sistemas artificiais no contexto da arte sob a filosofia dos objetos técnicos desenvolvida por Gilbert Simondon. O foco de nosso trabalho é posto sobre o processo de invenção de objetos técnicos para argumentar que a obra de arte, quando resultante desse processo, ressona ao artista e ao observador como um nó de sinergias existentes. Tais sinergias, emergentes dos acoplamentos entre diversos sistemas (o sistema mental do artista, do observador e o sistema da obra), são mantidas por ligações afetivas. Argumentamos que estes sistemas têm suas camadas de indeterminação e complexidade expandidas quando organismos naturais, como plantas, são hibridizados a eles.

Palavras-chave: Planta. Ressonância. Interafectividade. Interação. Híbrido.

\begin{abstract}
:
This communication will drawn upon Gilbert Simondon's philosophy of technical objects to investigate the coupling of plants and artificial systems in the context of art. The focus will be placed on the process of inventing technical objects, arguing that the artwork, when resulting from such process, resonates to the artist and the observer as a node of existing synergies. These synergies, emergent from the coupling of several systems (the mental system of the artist, the observer and the artwork) are maintained by affective bonds. We argue that these systems have their margin of indetermination and complexity expanded when natural living organisms, such as plants, are hybridized to them.
\end{abstract}

Keywords: Plant. Resonance. Inter-affectivity. Interaction. Hybrid.

NÓBREGA, Carlos Augusto Moreira da. Plantas, máquinas e interafectividade. Informática na Educação: teoria \& prática, Porto Alegre, v. 15, n. 1, p. 139-145, jan./jun. 2012.

\section{Carlos Augusto Moreira da Nóbrega}

Universidade Federal do Rio de Janeiro

\section{0 objeto técnico}

$\boldsymbol{5}^{\mathrm{m}}$

m seu livro Du mode d'existence des objets techniques, o filósofo francês Gilbert Simondon (1989) afirma que o objeto técnico deve ser entendido a partir de seu processo de individuação. Para Simondon, o conceito de tecnologia, longe de ser pensado em termos de funções utilitárias, se revela sob a perspectiva de sistemas de invenção pelos quais objetos técnicos adquirem sua individuação através do processo que o filósofo veio a denominar "concretização". Em sua visão, é através desse processo que o objeto técnico evolui em direção ao objeto natural, porém, sem nunca chegar a alcançá-lo em sua plenitude, podendo apenas assemelhar-se a ele. Enquanto o objeto natural é concreto desde seu início, objetos técnicos tendem à sua concretude através de um processo, sendo essa uma fundamental distinção entre os dois. Mesmo no mais concreto dos objetos técnicos sempre restará uma quantidade de abs- 
tração ${ }^{1}$. Dessa maneira, o objeto técnico, em seu processo de concretização, é encontrado entre sua forma mais abstrata, o esquema, a idéia, e o organismo natural, um ser em sua plena concretude.Uma das questões que se colocam subseqüentes a esse ponto de vista é: o que se dá quando um ser vivo e um objeto técnico são articulados em conjunto como organismo híbrido?

À luz de Simondon, as máquinas não devem se opor aos homens posto que ambos são constituídos segundo um processo em comum. Sob o modo de invenção máquinas são informadas (no sentido de serem trazidas à forma) pelo homem, ou seja, tendo o homem como mediadores no seu constante processo de individuação, ao mesmo tempo em que homens constroem uma visão de mundo através das máquinas e a maneira de tais invenções existirem no mundo. Nesse sentido, Simondon nos parece apontar para a importância do processo de invenção na construção do diálogo entre natureza e máquina, assim como da visibilidade dessa relação. Um outro ponto colocado por Simondon é que a máquina será mais eficiente em seu fazer na medida em que sua margem de indeterminação aumenta. Simondon apresenta através dessa afirmação uma crítica do automatismo, no sentido que, segundo ele, o grau de perfeição e tecnicidade de uma máquina não depende essencialmente na sua capacidade de automação pois "a fim de tornar uma máquina automática, é necessário sacrificar muitas das suas possibilidades funcionais e muitas das suas utilizações possíveis" (SIMONDON, 1980, p.3). Além disso, o automatismo crescente em máquinas esconde

1 A quantidade de abstração a que nos referimos corresponde à idéia de forma abstrata, mais primitiva (SIMONDON, 1980, p.14), na qual partes de um dado objeto técnico ainda são articuladas como constituintes de um problema isolado, ainda sem integração coerente e sinergética com o todo. Essa fase é vista principalmente no projeto esquemático do objeto ainda em concepção. a sua "margem de indeterminação" (SIMONDON, 1980, p. 4). Segundo Simondon, é tal margem de indeterminação que "permite a sensibilidade da máquina à informação exterior" (SIMONDON, 1980, p 4). Uma máquina puramente automática é um sistema fechado. Por sua vez, uma máquina com tecnicidade superior é uma máquina aberta que incorpora o homem como o "organizador permanente como um intérprete vivo das máquinas em suas inter-relações" (SIMONDON, 1980). Essas idéias lançam alguma luz sobre nossa questão inicial a respeito da hibridação entre máquinas e seres vivos. Voltaremos a ela a seguir.

\section{Acoplando plantas e máquinas}

No contexto da prática artística, por décadas temos testemunhado a transição da criação de obras fechadas para obras abertas. Tal movimento exalta o observador como fundamental parte no complexo artista, trabalho de arte, observador, dentro do qual o observador, através de um processo de experimentação da obra, ativa o conjunto. O observador é aquele que atribui significado ao sistema, que, por sua vez, deve ter uma considerável "margem de indeterminação" para que seja possível incorporar a presença experiencial do observador e suas ações. No momento em que arte joga com a construção de sistemas tecnologicamente assistidos, a noção de "margem de indeterminação" na obra torna-se ainda mais relevante. Em nosso caso, sistemas híbridos de plantas e máquinas, o mesmo deve ser considerado não apenas no sentido de suas possibilidades funcionais, por exemplo: fazer uso da máquina como prótese amplificadora de comportamento orgânico vivo (no caso a planta) através do certo automatismo, ou, inversamente, injetar na máquina variáveis de funções orgânicas de maneira a atribuir àquela funcionalidade biônica. De outro modo, par- 
tindo do ponto de vista sensível, estético, pensamos que ao se trazer a natureza em diálogo com a máquina, tal hibridação produz uma complexidade derivada das diversas camadas de significados e funções sistêmicas em sinergia. Se máquinas, conforme propõe Simondon, evoluem em direção à natureza através de um processo de concretização, o acoplamento desses dois sistemas na forma de um indivíduo parece redirecionar os vetores evolucionários de máquinas e natureza de forma evidentemente imbricada rumo ao horizonte de uma certa ecologia híbrida. Tais sistemas híbridos, em sua complexidade, são carregados de significados potencialmente abertos à experiência do observador. Podemos dizer que do ponto de vista da experiência interrelacional observador-trabalho de arte, sistemas híbridos não demandam apenas interação por parte do observador, mas que o mesmo se engaje em processo dialógico com o sistema de forma a que ambos possam expressar sua maneira de existência no mundo. Para o observador a experiência de tal sistema complexo envolve a fruição de suas diversas partes (naturais e artificiais) colocadas em contexto, assim como das ligações afectivas ${ }^{2}$ que se

20 termo afecto é usado nessa comunicação para propor que campos de intensidade são ativados no relacionamento entre o trabalho de arte, o observador e o artista, segundo processos de invenção e fruição da obra. Para tornar clara essa idéia iremos recorrer ao conceito de Spinoza "affectus", uma palavra latina que, segundo Deleuze (1978), poderia ser traduzida pelo termo ingles "affect", aqui aplicado como afecto. Deluze afirma que afecto, seguindo a lógica de Spinoza, significa "variação [...], contínua variação da força de existir, na medida em que essa variação é determinada pelas idéias que um possui" (DELEUZE, 1978). Não redutível a idéia propriamente dita, nem a comparação conceitual entre idéias, afecto se refere em verdade a "transição vivida ou passagem vivida de um grau de perfeição a outro, na medida em que essa passagem é determinada por idéias; mas nela mesma não se constituindo uma idéia, mas sim afecto" (DELEUZE, 1978.). Nesse sentido, afecto é sugerido na presente comunicação como a energia fluidora que interconecta a relação sinergética entre o trabalho de arte, o observador e o artista. Seguindo a lógica de Simondon (1980, p. 62) poderíamos dizer que num dado ambiente, no qual o trabalho de arte ressona ao observador, assim como ao seu inventor, afecto intermediaria as sinergias entre os modos ativam em ressonância às sinergias entre os demais agentes desse sistema. Que ligações seriam essas?

\section{Segundo Simondon:}

Somos capazes de criar seres técnicos, porque temos dentro de nós mesmos um conjunto de relações e uma associação matéria-forma que é notavelmente semelhante ao que nós estabelecemos no objeto técnico. A relação entre o pensamento e vida é análoga à relação entre um objeto técnico estruturado e o ambiente natural. O objeto técnico é um objeto individualizado é um objeto inventado, produto do jogo de causalidades entre vida e pensamento no homem. (SIMONDON, 1980, p. 66)

\section{Ainda:}

Invenção, que significa a criação de um indivíduo, pressupõe um conhecimento intuitivo da [tecnicidade] $^{3}$ de elementos por parte do inventor. Invenção ocorre em um nível intermediário entre o concreto e o abstrato, o nível dos diagramas, o que implica a antecipação da existência e coerência de suas representações - aquelas imagens que mascaram [tecnicidade] com uma camada de símbolos que fazem parte de uma sistemática e dinâmica imaginária. (SIMONDON, 1980, p. 86)

Podemos dizer que concretização ou individuação, segundo a perspectiva de Simondon, refere-se ao processo pelo qual objetos técnicos vêm a se tornar coerentes. Enquanto organismos vivos são coerentes por natureza, objetos técnicos tornam-se coerentes através de um processo de invenção e concretização. Ainda, segundo a lógica de Simondon, podemos dizer que a individuação de um objeto

de pensamento e intensidades de cada indivíduo desse sistema. Este é o argumento central a ser desenvolvido nessa comunicação.

3 A palavra francesa originalmente empregada é "technicité". Apesar do fato da tradução inglesa para esse trabalho ter usado o termo "technicality", estamos adotando o termo tecnicidade da mesma forma que adotado por alguns acadêmmicos (STIEGLER, 1998, MACKENZIE, 2002). 
técnico deriva de estados de ressonância entre as operações mentais e físicas do inventor e as sinergias internas do objeto sob invenção. Concluímos portanto que a criação de objetos de arte corresponde à invenção de sistemas coerentes interligados ao artista, assim como ao receptor da obra, por estados de ressonância. Nos termos de Simondon, a percepção de tais estados de ressonância é considerada "afecto"4.

Por essa via deduzimos que a criação de obras de arte implica a formação de vínculos afetivos. Interagir com a obra corresponderia ao processo de modulação de tais conexões, suas intensidades e ressonâncias. Sugerimos que processos interativos na arte sejam considerados em termos de interligações afetivas ou inter-afetividade. Considerados por essa ótica, tais processos não espelhariam tão somente aspectos de reciprocidade entre homem-máquina no nível de funcionalidades técnicas, mas evidenciariam níveis de ressonância afetivo, que enredam substancialmente o complexo artista, trabalho de arte, observador. É nesse sentido que podemos pensar essa tríade relacional em sua base orgânica, integrativa, tecnológica na forma de um hiperorganismo ${ }^{5}$.

Tendo em vista esse nível de interconectividade iremos considerar a seguir a hibridação entre plantas e sistemas artificiais na arte. Desenvolveremos o argumento que o acoplamento de plantas (sistemas orgânicos vivos) à organismos artificiais acrescenta camadas complexas e indeterminação ao sistema e consequentemente à relação homemmáquina. Para concluir nossa comunicação

\footnotetext{
4 Aqui o termo afecto é empregado para diferenciar-se de de afeto, se aproximando da forma como afecto é empregado por Gilles Deleuze (1997).
}

5 Sobre o conceito de hiperorganismo ver o livro desse autor: Thinking Hyperorganisms. Art, technology, coherence, connectedness, and the integrative field (NÓBREGA, 2010). analisaremos a trabalho de arte "Breathing", um exemplo da hibridação entre plantas e sistemas artificiais como experiência artística.

\section{Plantas e sistemas artificiais como arte}

Quando plantas e máquinas são acopladas de forma híbrida para constituição de uma obra artística devemos pensar tal complexo como um sistema, e como tal, devemos considerar a interação de suas diversas camadas significantes. Em "Breathing", trabalho desenvolvido pelo autor em 2008 (ver fig. 1) plantas são incorporadas ao sistema levando-se em conta sua dimensão do ponto de vista popular, científico e pseudocientífico. É essa camada conceitual sistêmica que é apropriada pelo processo de invenção (esquemas mentais e funcionais na obra) e que é esperada ressonar à fruição do observador. "Breathing" é uma obra de arte com base em uma criatura híbrida feita de um organismo vivo (uma planta) e um sistema artificial. Esse conjunto, pensado sob o conceito de hiperorganismo, responde ao seu ambiente através de luz própria, movimentos estruturais e do ruído de partes mecânicas. Respirar é a melhor maneira de interagir com essa criatura. Esse trabalho é o resultado de uma investigação em plantas como agentes sensíveis para a criação de arte.

Esse projeto foi construído com base no Arduino, plataforma open-source de computação física, interligado a um circuito eletrônico para medição de condutância em folhas vegetais. Uma programação do sistema define o comportamento global da criatura que se manifesta segundo reações eletrofisiológicas da planta à mudanças ambientais. O núcleo conectivo desse sistema híbrido é um circuito eletrônico conhecido como "Wheatstone bridge" (ponte de resistores) no qual um dos componentes ativos (um dos resistores) é substituído por 


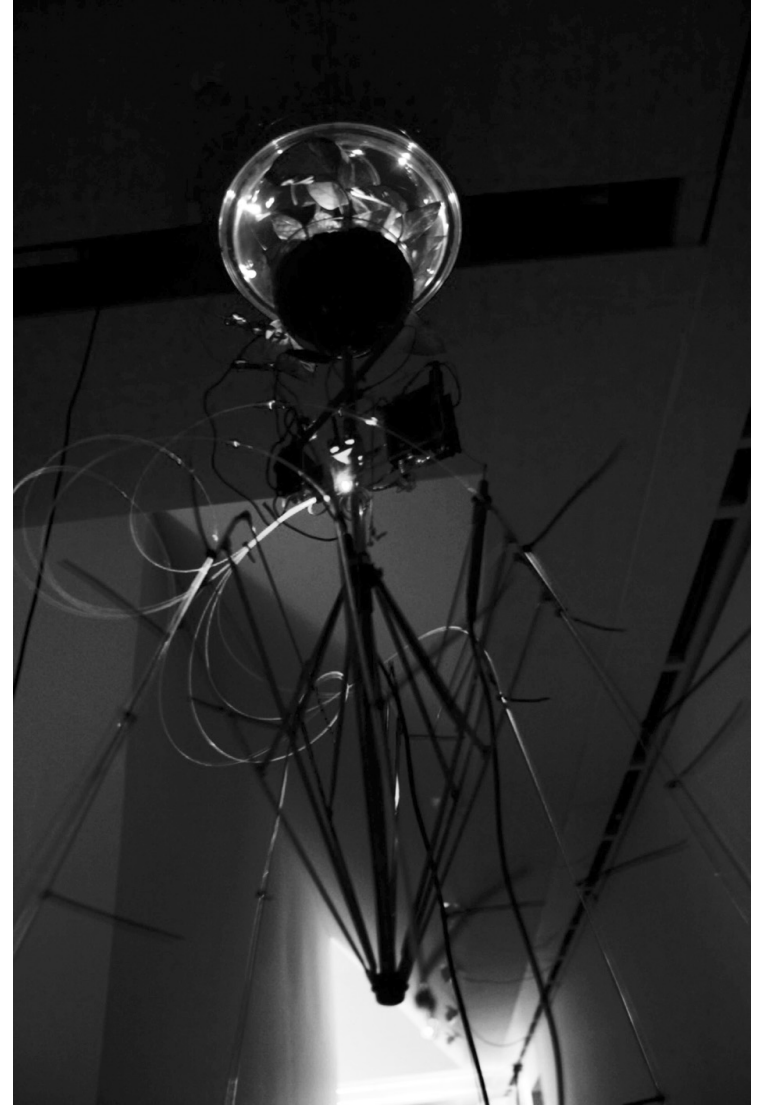

Figura 1: Respiração. Foto por Brínea Costa.

um componente orgânico - no caso uma folha vegetal. Essa folha, ligada ao circuito através de eletrodos customizados, funciona como uma resistência orgânica. Qualquer variação do nível de condutância elétrica na folha monitorada, que responde sensivelmente à alterações das condições ambientais, desequilibra a ponte que, por sua vez, produz uma diferença de voltagem em sua saída. Este sinal é amplificado, analisado pelo microcontrolador Arduino e transduzido ${ }^{6}$ em movimento, luzes

6 No sentido de transdução entre diferentes fontes de energia. Tais fontes de entrada, analógicas refletem em saídas digitais que são moduladas ao longo da experiência da obra. Dessa forma todo sistema é transformado em sinergia com a fruição do trabalho-de-arte pelo público.

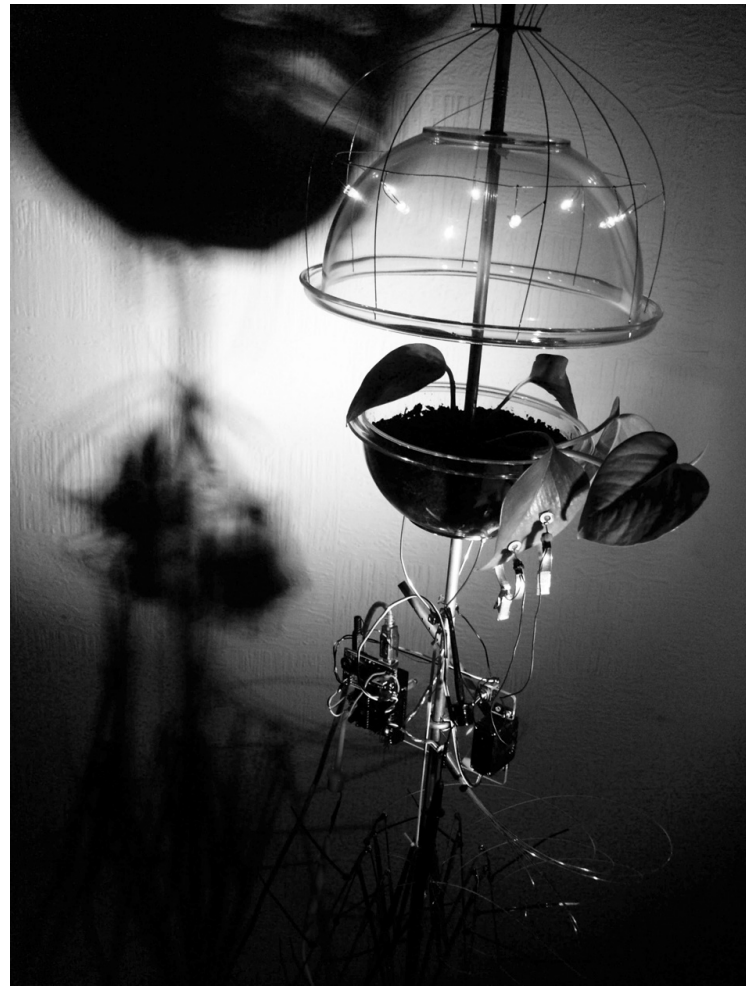

Figura 2: Estrutura de respiração. Foto por Guto Nóbrega.

e cores. Um servomecanismo ativa pernas mecânicas que se contraem e se expandem radialmente. Diodos emissores de luz (LEDs) colocados sobre uma cúpula transparente piscam em sequência, de maneira lenta ou rápida, de acordo com as alterações eletrofisiológicas da planta. Um diodo emissor de luz RGB (LED RGB) muda de cor de acordo com as reações da planta e sua luz é transmitida através de fibras óticas para a extremidade inferior da criatura (ver fig. 2 e 3). Padrões coloridos em movimento são projetadas no chão quando as pernas mecânicas estão em movimento.

Uma das interações possíveis com a criatura ocorre através do ato de respirar. Quando o observador de "Breathing" exala seu ar interno nas proximidades das folhas do híbrido as variações elétricas na superfície das folhas 


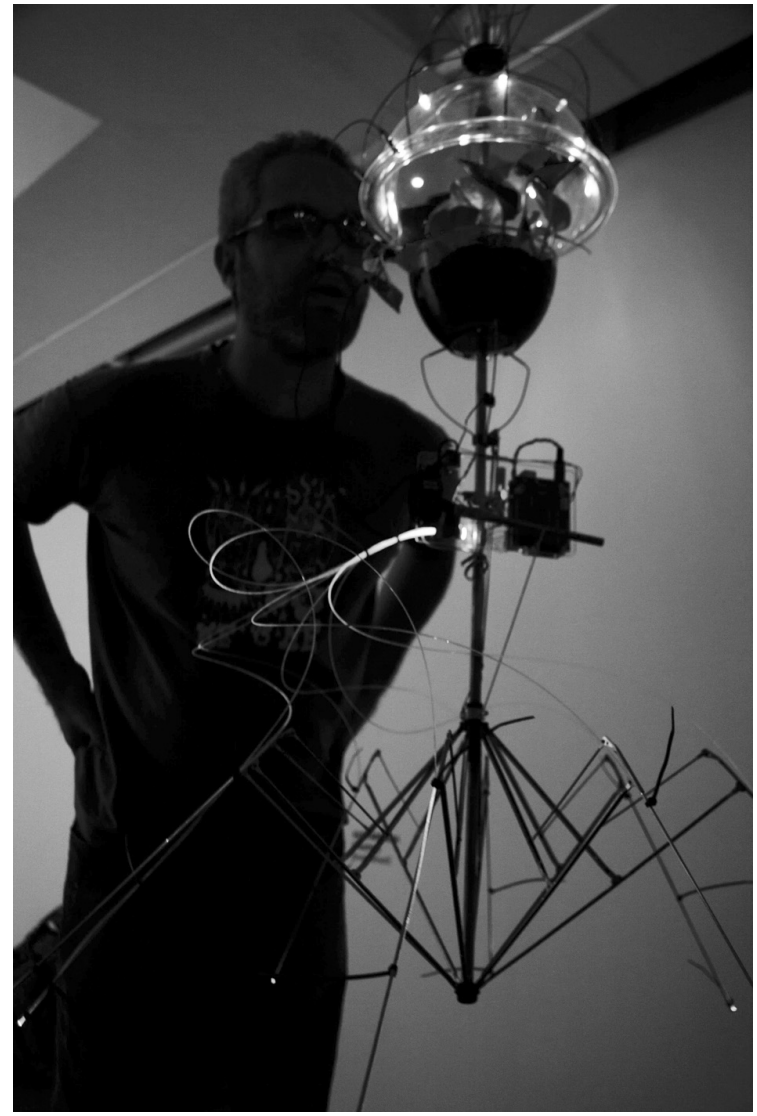

Figura 3: Respirando perto da criatura. Foto por Brínea Costa

são alteradas e amplificados pelo sistema resultando no comportamento dessa criatura.

A experiência de "Breathing" coloca o observador em um lugar instável, que é o lugar criado pela arte. O observador confronta um organismo que resulta de uma colagem sistêmica entre elementos naturais e artificiais, cujas camadas de significação se articulam sinergeticamente para prover ao observador uma experiência sensível. A obra de arte pode ser assim pensada como um nó de informações através do qual o observador pode ressonar ao artista através de uma interligação poética, afetiva. A obra desloca o comportamento natural da planta, na maioria das vezes despercebidos pelos nossos sentidos, para uma dimensão ampliada. Ao se interagir com as folhas vegetais o participante dessa experiência estética não está apenas acionando as funções automatizadas da máquina, mas, acima de tudo, ativando por meio de sua presença uma relação afetiva que decorre de sua própria interconexão ao sistema. Em decorrência dessa relação as seguintes questões podem ser formuladas: como a planta percebe ou sente essa relação? Somo percebidos de alguma forma por esse híbrido? Como essa experiência afeta a minha consciência sobre as plantas, máquinas e o meio em que vivemos? Todas as questões possíveis sobre as plantas são amplificadas pelo sistema ao qual ela se encontra acoplada. Mesmo não havendo respostas concretas para tais questões, elas alimentam o desejo da arte. Elas abrem o horizonte para novos diálogos com o mundo em que vivemos, dissolvendo nesse sentido antigas dicotomias ao levar em consideração os objetos técnicos, não como uma ameaça contra a natureza mas, de acordo com Simondon, como possíveis "mediadores entre o homem e a natureza" (SIMONDON, 1980, p.1). A partir destes diálogos improváveis, contextualizados na experiência da arte, novas ecologias em curso vem sendo mapeadas, assim como os homems e suas invenções tem sido alçados a novos territórios criativos. 


\section{Referências}

DELEUZE, G. Spinoza. Cours Vincennes, 1978. Disponível em:

<http://www.webdeleuze.com/php/texte.php?cle=14\&groupe=Spinoza\&langue=2> Data de acesso:

$21 / 12 / 2011$.

DELEuZE, G; F. GuATtARI. O que é a Filosofia? São Paulo: Editora 34, 1997.

MACKENZIE, A. Transductions: bodies and machines at speed. New York: Continuum International Publishing Group, 2002. 231 p.

NÓBREGA, C. Thinking Hyperorganism: Art, technology, coherence, connectedness, and the integrative field. Saarbrücken, Germany: LAP Lambert Academic Publishing, 2010.

SIMONDON, G. On the Mode of Existence of Technical Objects. English translation of "Du mode d'existence des objets techniques". London: University of Western Ontario, 1980.

SIMONDON, G. Du mode d'existence des objets techniques. Paris: Aubier: Editions Montaigne, 1989.

STIEGLER, B. Technics and Time: The fault of Epimetheus. Stanford, California: Stanford University Press, 1998.

Recebido em: 01 de setembro de 2011

Aprovado para publicação em: 03 de novembro de 2011

\section{Carlos Augusto Moreira da Nóbrega}

Doutor pelo Planetary Collegium - Plymouth University - UK. Coordenador do NANO. Núcleo de Arte e Novos Organismos - EBA- UFRJ. Professor do Programa de Pós Graduação em Artes Visuais da Universidade Federal do Rio de Janeiro - Rio de Janeiro/RJ - Brasil. E-mail: gutonobrega@gmail.com 